\title{
Differential Sleep-Wake Sensitivity of Gonadotropin-Releasing Hormone Secretion to Progesterone Inhibition in Early Pubertal Girls
}

\author{
Jessicah S.P. Collins ${ }^{a, b}$ John C. Marshall ${ }^{a, b} \quad$ Christopher R. McCartney ${ }^{a, b}$ \\ aDivision of Endocrinology and Metabolism, Department of Medicine, and ${ }^{b}$ Center for Research in Reproduction, \\ University of Virginia Health System, Charlottesville, Va., USA
}

\section{Key Words}

Gonadotropin-releasing hormone • Luteinizing hormone •

Progesterone $\cdot$ Puberty $\cdot$ Female reproduction

\begin{abstract}
Context: Early pubertal luteinizing hormone (LH), and by inference gonadotropin-releasing hormone $(\mathrm{GnRH})$, pulse secretion is marked by high nocturnal but low daytime frequency; however, the underlying mechanisms remain unclear. Plasma concentrations of progesterone, the major regulator of $\mathrm{GnRH}$ frequency in women, increase in the early morning in early pubertal girls and may help slow daytime GnRH frequency. Objective: To evaluate the effect of progesterone on LH pulse frequency in early to mid-pubertal girls. Design: Controlled interventional study. Setting: General clinical research center. Participants: Eighteen nonobese, non-hyperandrogenemic Tanner 1-3 girls. Intervention: Twelve-hour (19:00-07:00 h) blood sampling with or without oral progesterone administration $(25-50 \mathrm{mg}$ at 16:00 and 20:00 h). Main Outcome Measure: LH pulse frequency. Results: Girls receiving progesterone $(n=5)$ exhibited lower 12-hour LH pulse frequency than controls $(n=13)$, but this difference was not statistically significant (average interpulse intervals $196.0 \pm 61.9$ and $160.4 \pm 67.1 \mathrm{~min}$, respectively; $p=0.2793$ ). In contrast to controls, however, girls receiving progesterone exhibited no LH pulses during waking hours (19:00-23:00 h; estimated interpulse interval 326.0
\end{abstract}

\pm 52.7 vs. $212.0 \pm 120.9$ min; $p=0.0376)$, while nighttime (23:00-07:00 h) interpulse intervals were similar (174.8 \pm 62.0 vs. $167.5 \pm 76.9 \mathrm{~min}$, respectively; $p=0.7750$ ). Conclusions: Exogenous progesterone acutely suppressed daytime, but not nocturnal, LH pulse frequency in early to midpubertal girls, suggesting that GnRH pulse frequency is differentially regulated by progesterone depending on sleep status.

Copyright $\odot 2012$ S. Karger AG, Basel

\section{Introduction}

Early puberty is characterized by sleep-entrained increases of luteinizing hormone $(\mathrm{LH})$ - and by inference gonadotropin-releasing hormone $(\mathrm{GnRH})$ - pulse frequency and amplitude with a subsequent reduction of LH release during waking hours [1-3]. Mechanisms controlling day-night changes of $\mathrm{GnRH}$ secretion are unclear. However, in contrast to normal early pubertal girls, age-matched girls with gonadal dysgenesis demonstrate no day-night difference of LH pulse frequency [3], suggesting that an ovarian factor plays a role in this regard.

Progesterone is the major regulator of $\mathrm{GnRH}$ pulse frequency in adult women and is responsible for $\mathrm{GnRH}$ pulse frequency suppression during the luteal phase. Exogenous progesterone reduces $\mathrm{LH}$ pulse frequency in

\section{KARGER \\ Fax +4161306 1234 \\ E-Mail karger@karger.ch}

www.karger.com
(C) 2012 S. Karger AG, Basel

0028-3835/12/0963-0222\$38.00/0

Accessible online at:

www.karger.com/nen
Christopher R. McCartney

Division of Endocrinology and Metabolism, Department of Medicine

Box 800391, University of Virginia Health System

Charlottesville, VA 22908 (USA)

Tel. +1 434982 6324, E-Mail cm2hq@virginia.edu 
Table 1. Baseline characteristics

\begin{tabular}{lcc}
\hline & Progesterone group $(\mathrm{n}=5)$ & Controls $(\mathrm{n}=13)$ \\
\hline Tanner stage & $2.2 \pm 0.8(2,1-3)$ & $2.2 \pm 0.8(2,1-3)$ \\
Age, years & $11.1 \pm 1.5(11.0,9.2-13.0)$ & $11.0 \pm 1.9(10.8,7.4-13.5)$ \\
BMI & $16.4 \pm 1.4(15.6,15.1-18.3)$ & $18.4 \pm 2.8(17.2,14.6-23.1)$ \\
BMI-for-age percentile & $31.6 \pm 21.1(34.0,10.0-58.0)$ & $54.6 \pm 30.8(56.3,5.1-92.8)$ \\
Estradiol, pg/ml & $39.6 \pm 9.4(39.3,26.6-50.0)$ & $38.0 \pm 16.3(40.2,5.1-68.2)$ \\
Total testosterone, ng/dl & $9.3 \pm 3.5(11.0,5.0-12.3)$ & $8.3 \pm 5.5(6.3,5.0-23.5)$ \\
SHBG, nmol/l & $72.1 \pm 20.4(68.7,52.1-103.0)$ & $55.3 \pm 17.3(51.0,27.4-86.4)$ \\
Free testosterone, pmol/l & $3.4 \pm 1.3(3.0,2.3-5.3)$ & $4.0 \pm 2.9(2.8,1.2-11.0)$ \\
DHEAS, $\mu$ g/dl & $49.2 \pm 29.5(50.2,12.7-79.0)$ & $52.6 \pm 37.7(45.9,6.0-143.0)$ \\
Fasting insulin, $\mu \mathrm{U} / \mathrm{ml}$ & $5.5 \pm 3.5(5.6,1.3-9.7)$ & $10.9 \pm 6.3(10.8,1.7-23.3)$ \\
Fasting glucose, $\mathrm{mg} / \mathrm{dl}$ & $85.2 \pm 7.9(88,72-93)$ & $84.4 \pm 4.4(84,79-91)$ \\
\hline
\end{tabular}

Data are presented as mean \pm SD (median, minimum-maximum). BMI = Body mass index; $\mathrm{SHBG}=$ sex hormone-binding globulin; DHEAS = dehydroepiandrosterone sulfate. All comparisons (progesterone group vs. controls) were non-significant ( $\mathrm{p}>0.05)$, although there was a trend toward lower SHBG and higher insulin values in controls ( $\mathrm{p}=0.0619$ and 0.0966 , respectively). To convert from conventional to SI units: estradiol $\times 3.671$ (for pmol/l); total testosterone $\times 0.0347$ (for nmol/l); DHEAS $\times 27.21$ (for $\mathrm{nmol} / \mathrm{l})$; insulin $\times 6.945($ for $\mathrm{pmol} / \mathrm{l})$; glucose $\times 0.0555$ (for $\mathrm{mmol} / \mathrm{l})$.

postmenopausal women [4] and in ovulatory women during the follicular phase [5]. In early pubertal girls, levels of sex steroids (including progesterone) increase overnight, peaking in the early morning hours [6]. Given these findings, we have previously suggested that morning increases of progesterone suppress daytime GnRH pulse frequency in early pubertal girls, in part accounting for day-night changes of GnRH frequency [7]. However, few data are available regarding sex steroid feedback on pulsatile LH secretion in early pubertal girls. In one study involving 2 girls in each of the five Tanner stages [8], raising estradiol levels 2.5-fold appeared to reduce $\mathrm{LH}$ pulse amplitude without changing pulse frequency. To our knowledge, there are no published data regarding the influence of progesterone on $\mathrm{LH}$ secretion in early pubertal girls. We hypothesized that evening administration of progesterone would suppress nocturnal LH pulse frequency in early to mid-pubertal girls, therefore mitigating the day-night increase of $\mathrm{LH}$ pulse frequency.

\section{Materials and Methods}

Eighteen early to mid-pubertal girls (Tanner breast stages $1-3)$, aged 7 to 14 years, were recruited through local advertisements. Tanner 1 girls were included only if estradiol levels were $>20 \mathrm{pg} / \mathrm{ml}$ (suggesting pubertal activation of GnRH secretion). All subjects were healthy and non-obese (body mass index-for- age percentile $<95$ ), had no evidence of hyperandrogenism, and were taking no drugs known to affect the reproductive axis. Subject characteristics are shown in table 1 .

\section{Study Procedures}

Study procedures were approved by the Institutional Review Board at the University of Virginia (UVA). Informed assent and consent were obtained from subjects and parents, respectively. Each volunteer underwent a detailed medical history, physical examination, and fasting laboratory evaluation to ensure good health and normal hormonal parameters.

Subjects were admitted to the General Clinical Research Center at 14:00 h, and a forearm intravenous catheter was placed. Two Tanner 3 control subjects were postmenarcheal for less than 1 year and were admitted between cycle days 7 and 10; all remaining subjects were premenarcheal. Eight subjects were randomized to receive either oral micronized progesterone ( $25 \mathrm{mg}$ for 4 subjects and $50 \mathrm{mg}$ for 1 subject weighing $>42 \mathrm{~kg}$ ) at 16:00 and 20:00 h $(n=5)$ or placebo $(n=3)$. These weight-based doses were chosen based on previous experience, and we aimed to achieve progesterone concentrations approximating $3-5 \mathrm{ng} / \mathrm{ml}$. As planned before study initiation, the control group also included girls who received no medication but otherwise underwent identical procedures $(n=10)$. (Results were similar between those receiving placebo and those receiving no medication.) Data for some of these latter subjects have been reported [7].

Frequent blood samples were obtained between 19:00 and 07:00 h: every $10 \mathrm{~min}$ for LH, every $2 \mathrm{~h}$ for follicle-stimulating hormone (FSH), and every $30 \mathrm{~min}$ for progesterone, estradiol, and testosterone. Fasting samples were drawn at 07:00 h for glucose, insulin, sex hormone-binding globulin, and dehydroepiandrosterone sulfate. Lights were extinguished at 23:00 h to facilitate sleep, which was recorded by trained observers. 
Fig. 1. Representative LH time series from Tanner 2 girls who did (left) and did not (right) receive progesterone. Asterisks denote significant $\mathrm{LH}$ pulses.

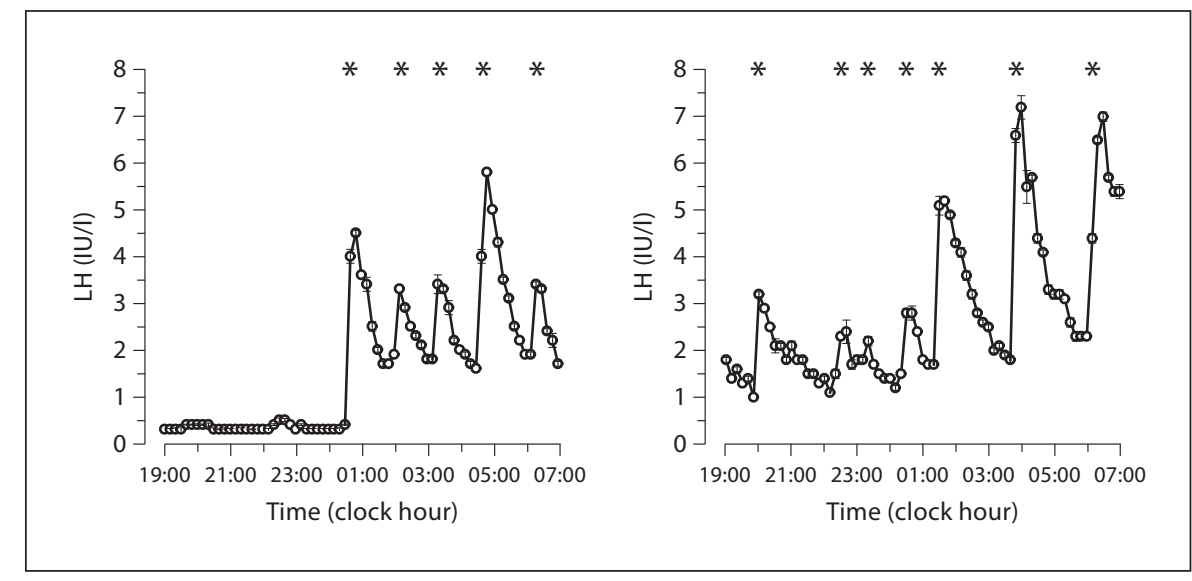

Hormone Measurements

Samples were analyzed at the UVA Center for Research in Reproduction Ligand Core Laboratory. Samples from an individual were analyzed in duplicate in the same assay for each hormone. Manufacturer, assay sensitivity, and intra- and inter-assay coefficients of variation for all hormone measurements have been reported [7].

\section{Data and Statistical Analysis}

LH pulses were identified using the computerized pulse detection algorithm Cluster 7 [9]. We employed the same analysis parameters described previously [10]: test nadir and peak size of 2 $\times 2$, with a t statistic of 2.45 for both upstroke and downstroke. If the amplitude of a Cluster 7-detected LH pulse was less than the range of the intra-assay variability for our LH chemiluminescence assay, it was not considered a pulse in the subsequent analysis [10]. Specifically, the following pulse characteristics were grounds for exclusion: a peak less than 0.5 with an amplitude less than 0.1 ; a peak from 0.5 to 1 with an amplitude less than 0.25 ; a peak from 1 to 5 with an amplitude less than 0.5 , and a peak greater than 5 with an amplitude less than 1 (all units being IU/l). Pulse location was defined as the time point at which the LH increment first exceeded that required for acceptance of pulse.

The pre-specified primary end point was 12-hour LH pulse frequency (19:00-07:00 h), which we hypothesized would be lower in girls receiving progesterone. Interpulse intervals were calculated as previously described [10]. Both the absolute number of LH pulses over $12 \mathrm{~h}$ and the average 12-hour interpulse interval were determined, and interpulse intervals were compared between girls receiving progesterone and controls. As a secondary analysis, we compared LH frequency in 4-hour time blocks to assess for group differences related to sleep status. The 19:00-23:00 h block, when subjects were awake, served as a surrogate for daytime (due to blood volume restrictions), and subjects were asleep during the majority of the 23:00-03:00 and 03:00-07:00 h time blocks. All comparisons were performed using the Wilcoxon rank-sum test, which is based on ranks of observations and requires no assumptions about the underlying distribution of data. Hypothesis tests were two-sided and conducted at the 0.05 level of significance. Results are reported as mean \pm SD unless otherwise specified.

\section{Results}

Twelve-hour mean serum progesterone was $5.08 \pm$ $1.38 \mathrm{ng} / \mathrm{ml}$ in girls receiving progesterone (baseline values, $0.24 \pm 0.09 \mathrm{ng} / \mathrm{ml}$ ) and remained elevated throughout sampling (19:00-23:00 h, 5.79 \pm 1.94; 23:00-03:00 h, $5.42 \pm 1.74 ; 03: 00-07: 00 \mathrm{~h}, 4.02 \pm 1.89 \mathrm{ng} / \mathrm{ml})$. Twelvehour progesterone was $0.32 \pm 0.08 \mathrm{ng} / \mathrm{ml}$ in controls. To convert the data from conventional to SI units, multiply the progesterone values by 3.18 (for nmol/l).

Subjects receiving progesterone exhibited an approximately 25\% lower 12-hour LH pulse frequency than controls, but this difference was not statistically significant. Controls had $4.9 \pm 2.1 \mathrm{LH}$ pulses/12 h, while girls receiving progesterone had $3.6 \pm 1.3 \mathrm{LH}$ pulses/12 h. The average 12-hour interpulse interval was $196.0 \pm 61.9 \mathrm{~min}$ in girls receiving progesterone and $160.4 \pm 67.1 \mathrm{~min}$ in controls $(\mathrm{p}=0.2793)$. No group differences were observed for 12-hour mean LH, 12-hour mean LH pulse amplitude, or 12-hour mean FSH ( $\mathrm{p}>0.3$ for all comparisons; data not shown).

In contrast to controls, who exhibited $0.29 \pm 0.30$ pulses/h during waking hours (19:00-23:00 h), girls receiving progesterone demonstrated no LH pulses while awake; however, nocturnal LH pulse frequencies were similar $(0.48 \pm 0.18$ vs. $0.45 \pm 0.17 \mathrm{pulses} / \mathrm{h}$, respectively). Accordingly, estimated daytime interpulse intervals were significantly longer in those receiving progesterone $(326.0 \pm 52.7$ vs. $212.0 \pm 120.9$ min, respectively; $\mathrm{p}=$ $0.0376)$, while nighttime interpulse intervals did not differ between the groups $(174.8 \pm 62.0$ vs. $167.5 \pm 76.9$ min, respectively; $\mathrm{p}=0.7750$ ). Representative examples of LH time series are shown in figure 1, and composite data are shown in figure $2 \mathrm{a}$. 


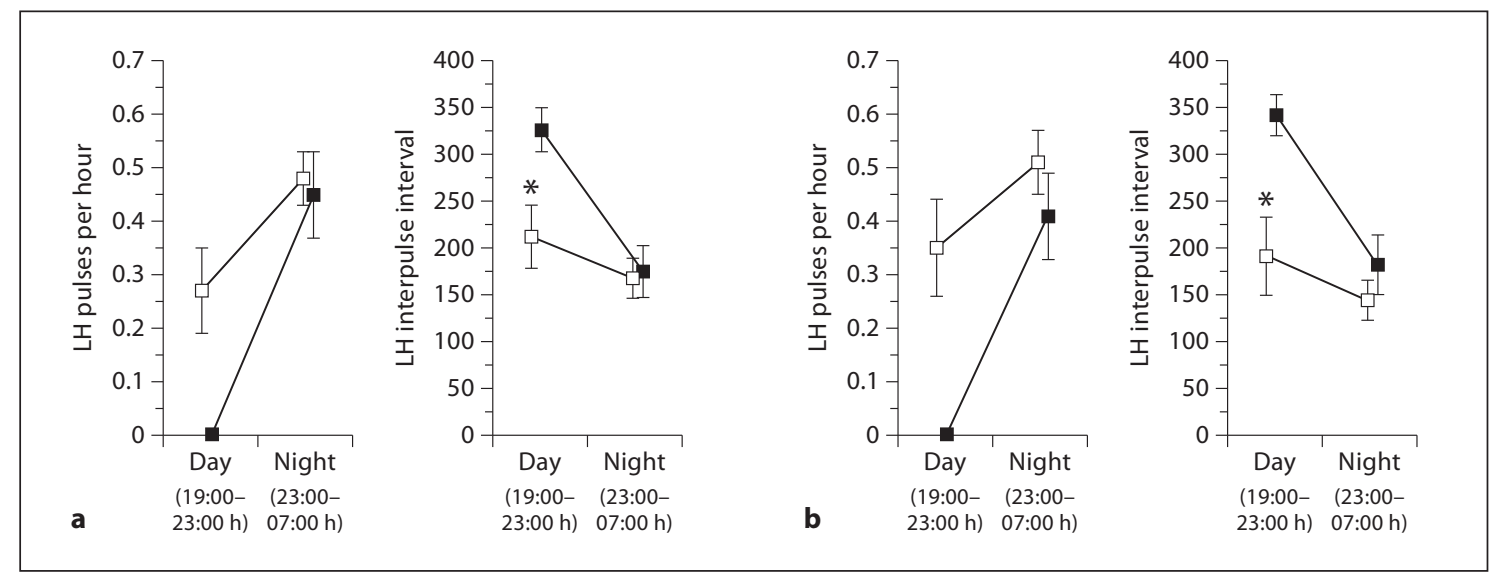

Fig. 2. a LH pulse frequency in Tanner $1-3$ girls who did (solid squares; Tanner stage $2.2 \pm 0.8 ; \mathrm{n}=5$ ) and did not (open squares; Tanner stage $2.2 \pm 0.8 ; \mathrm{n}=13$ ) receive oral progesterone. $\mathbf{b} \mathrm{LH}$ pulse frequency in Tanner 2-3 girls who did (solid squares; Tanner stage $2.5 \pm 0.6 ; n=4$ ) and did not (open squares; Tanner stage $2.5 \pm$ $0.5 ; \mathrm{n}=10)$ receive oral progesterone. Data are shown graphically as mean \pm SEM. ${ }^{*} \mathrm{p}<0.05$.

Since Tanner 1 girls are not generally expected to have demonstrable LH pulses during the 19:00-23:00 h time block [7], we repeated the analyses in Tanner 2-3 girls only. Compared to controls $(\mathrm{n}=10)$, Tanner $2-3$ girls receiving progesterone $(n=4)$ demonstrated a trend toward a lower 12 -hour pulse count $(3.3 \pm 1.3$ vs. $5.5 \pm 2.1 \mathrm{LH}$ pulses/12 h) and a longer mean interpulse interval (211.5 \pm 59.3 vs. $149.2 \pm 69.0$ min; $p=0.0999$ ). Daytime interpulse intervals were longer in those receiving progesterone $(342.5 \pm 43.5$ vs. $190.7 \pm 130.7$ min, respectively; $\mathrm{p}=0.0250$ ), while nighttime interpulse intervals were similar (fig. 2b). Excluding 2 recently postmenarcheal girls from analysis did not substantially alter the findings.

\section{Discussion}

We aimed to assess the potential role of progesterone negative feedback in directing day-night changes of $\mathrm{LH}$ $(\mathrm{GnRH})$ pulse frequency in early to mid-pubertal girls. We have hypothesized that early morning increases of progesterone reduce $\mathrm{GnRH}$ pulse frequency in early pubertal girls, in part accounting for day-night differences of $\mathrm{LH}$ pulse frequency [7]. We thus reasoned that early administration of exogenous progesterone (i.e. prior to the early morning increase of endogenous progesterone) would be associated with lower overnight LH pulse frequency. While LH pulse frequency (19:00-07:00 h) was approximately $25 \%$ lower in girls receiving exogenous progester- one, this difference was not statistically significant. However, further assessment of the data suggested that the trend toward lower 12-hour LH pulse frequency with progesterone was exclusively related to marked differences during the 19:00-23:00 h (awake) time block. Indeed, girls receiving progesterone had no demonstrable $\mathrm{LH}$ pulses during this time period. This finding suggests that, in early to mid-pubertal girls, progesterone acutely (within 3$7 \mathrm{~h}$ ) and markedly suppresses LH pulse frequency during waking hours, but not during sleep. Thus, there may be a differential sensitivity of GnRH pulse frequency to progesterone feedback depending on sleep status.

Limitations of the study are that progesterone concentrations achieved were supraphysiologic for pubertal stage, sleep was not formally evaluated, and we did not assess $\mathrm{LH}$ secretion beyond 07:00 $\mathrm{h}$. Additionally, the number of subjects receiving progesterone in this study was relatively small - a difficulty inherent to this field of study - and failure to formally demonstrate a group difference in 12-hour LH pulse frequencies may represent a type II error. Nonetheless, the current results strongly suggest a differential day-night suppression of $\mathrm{LH}$ $(\mathrm{GnRH})$ pulse frequency. Additional research is necessary to formally investigate the effect of physiologic progesterone levels on sleep-associated and waking LH frequency.

The regulation of $\mathrm{GnRH}$ secretion during puberty is highly complex and poorly understood. The pubertal increase of $\mathrm{GnRH}$ secretion appears to reflect the release of $\mathrm{GnRH}$ neurons from inhibition by higher CNS pathways 
(i.e. release from the 'neurobiological brake') and the maturation of crucial stimulatory and permissive factors such as kisspeptin, neurokinin B, and leptin [11-13]. Mechanisms underlying the characteristic sleep-wake patterns of GnRH secretion - patterns that change markedly across puberty in girls - are unknown. In early puberty, the GnRH pulse generator is quiescent during waking hours, but GnRH neuronal activity increases during sleep $[1,7]$. This likely reflects GnRH pulse generator stimulation (or release from inhibition) by higher CNS inputs during sleep. However, as puberty progresses, daytime $\mathrm{LH}(\mathrm{GnRH})$ pulse frequency gradually increases, while nighttime frequency remains remarkably constant at about 1 pulse every $2 \mathrm{~h}$ [7]. By late puberty, daytime LH pulse frequency exceeds nighttime frequency (i.e. frequency decreases overnight) - at least during the follicular phase [7]. The current study has informed a new working model regarding these changes of day-night LH pulse frequency across puberty [14]. Specifically, after the initiation of puberty, GnRH pulse frequency is controlled during waking hours by neuronal inputs/networks that are sensitive to progesterone negative feedback. However, during sleep, GnRH pulse frequency is controlled by neuronal inputs/networks that are not readily influenced by progesterone. Thus, LH frequency decreases during the day when the $\mathrm{GnRH}$ pulse generator is released from sleep inputs and is suppressed by progesterone. We hypothesize that, in early puberty, daytime $\mathrm{GnRH}$ frequency is low because of exquisite sensitivity to progesterone suppression. However, as puberty progresses, sensitivity of waking inputs to negative feedback decreases, perhaps related to rising testosterone concentrations, which can interfere with progesterone suppression of $\mathrm{GnRH}$ pulse frequency [15]. This allows waking $\mathrm{GnRH}$ pulse frequency to rise gradually, eventually exceeding sleep-associated pulse frequency.

The regulation of GnRH secretion across puberty has implications for both normal and abnormal physiology. The physiological relevance of day-night changes of $\mathrm{GnRH}$ pulse frequency during puberty is unclear. However, it is noteworthy that changes of $\mathrm{GnRH}$ pulse frequency can differentially influence LH and FSH secretion, with high GnRH frequencies favoring LH secretion and low frequencies favoring FSH secretion $[16,17]$. Thus, in early pubertal girls, low daytime GnRH pulse frequency may be important to support FSH secretion (and follicular development), while faster nighttime frequencies increase synthesis of LH - important for sex steroid production and eventual ovulation. Adolescent girls with hyperandrogenemia, which can be a precursor to polycystic ovary syndrome $[18,19]$, may not exhibit low awake and high sleep LH pulse frequencies during early puberty [14], and these girls have elevated daytime and nighttime $\mathrm{LH}$ frequencies during mid- and late puberty $[7,20]$. Some late adolescent girls with hyperandrogenemia have an impaired hypothalamic sensitivity to progesterone negative feedback, which likely contributes to high GnRH pulse frequency [21]. Impaired GnRH pulse generator suppression by progesterone during waking hours could help explain elevated daytime GnRH frequency - and diminished day-night changes of GnRH pulse frequency in some pubertal girls with hyperandrogenemia. Persistently rapid day-night $\mathrm{GnRH}$ pulses (e.g. absence of daytime slowing) could support the development of polycystic ovary syndrome by increasing $\mathrm{LH}$ and limiting FSH secretion [14].

In conclusion, mechanisms underlying the evolution of $\mathrm{GnRH}$ secretion across pubertal maturation remain enigmatic. The present results provide evidence that progesterone can acutely reduce $\mathrm{LH}$ pulse frequency during waking hours more so than during sleep. This concept may help explain the evolution of day-night LH pulse secretion across normal puberty.

\section{Acknowledgements}

We gratefully acknowledge Lauren Lockhart, MPH, Quirine Lamberts Okonkwo, $\mathrm{MD}$, and Amy Bellows, $\mathrm{PhD}$, for subject recruitment, study scheduling, and assistance with data management; Drs. Karen L. Knudsen, Susan K. Blank, Kristin D. Helm, Sandhya Chhabra, and Kathleen A. Prendergast for assistance with study oversight; the nurses and staff of the GCRC at the University of Virginia for the implementation of these sampling protocols, and the Center for Research in Reproduction Ligand Core Laboratory for the performance of all assays.

This work was supported by NIH K23 HD044742 (C.R.M.); NIH R01 HD058671 (C.R.M.); the Eunice Kennedy Shriver National Institute of Child Health and Human Development/National Institutes of Health through cooperative agreement U54 HD28934 as part of the Specialized Cooperative Centers Program in Reproduction and Infertility Research (J.C.M.); NIH F32 HD066855 (J.S.P.C.), and General Clinical Research Center Grant M01 RR00847.

\section{Disclosure Statement}

None of the authors has any potential conflicts of interest to declare. 


\section{References}

-1 Boyar R, Finkelstein J, Roffwarg H, Kapen S, Weitzman E, Hellman L: Synchronization of augmented luteinizing hormone secretion with sleep during puberty. N Engl J Med 1972;287:582-586.

$>2$ Apter D, Butzow TL, Laughlin GA, Yen SS: Gonadotropin-releasing hormone pulse generator activity during pubertal transition in girls: pulsatile and diurnal patterns of circulating gonadotropins. J Clin Endocrinol Metab 1993;76:940-949.

$>3$ Cemeroglu AP, Foster CM, Warner R, Kletter GB, Marshall JC, Kelch RP: Comparison of the neuroendocrine control of pubertal maturation in girls and boys with spontaneous puberty and in hypogonadal girls. J Clin Endocrinol Metab 1996;81:4352-4357.

4 Gill S, Lavoie HB, Bo-Abbas Y, Hall JE: Negative feedback effects of gonadal steroids are preserved with aging in postmenopausal women. J Clin Endocrinol Metab 2002;87: 2297-2302.

5 Soules MR, Steiner RA, Clifton DK, Cohen NL, Aksel S, Bremner WJ: Progesterone modulation of pulsatile luteinizing hormone secretion in normal women. J Clin Endocrinol Metab 1984;58:378-383.

6 McCartney CR, Blank SK, Prendergast KA, Chhabra S, Eagleson CA, Helm KD, Yoo R, Chang RJ, Foster CM, Caprio S, Marshall JC: Obesity and sex steroid changes across puberty: evidence for marked hyperandrogenemia in pre- and early pubertal obese girls. J Clin Endocrinol Metab 2007;92:430-436.

$>7$ McCartney CR, Prendergast KA, Blank SK, Helm KD, Chhabra S, Marshall JC: Maturation of luteinizing hormone (gonadotropinreleasing hormone) secretion across puberty: evidence for altered regulation in obese peripubertal girls. J Clin Endocrinol Metab 2009;94:56-66.
8 Cemeroglu AP, Kletter GB, Guo W, Brown MB, Kelch RP, Marshall JC, Padmanabhan $\mathrm{V}$, Foster CM: In pubertal girls, naloxone fails to reverse the suppression of luteinizing hormone secretion by estradiol. J Clin Endocrinol Metab 1998;83:3501-3506.

$>9$ Veldhuis JD, Johnson ML: Cluster analysis: a simple, versatile, and robust algorithm for endocrine pulse detection. Am J Physiol 1986;250:E486-E493.

10 McCartney CR, Blank SK, Marshall JC: Progesterone acutely increases LH pulse amplitude but does not acutely influence nocturnal LH pulse frequency slowing during the late follicular phase in women. Am J Physiol Endocrinol Metab 2007;292:E900-E906.

11 Plant TM: Hypothalamic control of the pituitary-gonadal axis in higher primates: key advances over the last two decades. J Neuroendocrinol 2008;20:719-726.

12 Oakley AE, Clifton DK, Steiner RA: Kisspeptin signaling in the brain. Endocr Rev 2009;30:713-743.

13 Terasawa E, Kurian JR, Guerriero KA, Kenealy BP, Hutz ED, Keen KL: Recent discoveries on the control of gonadotrophin-releasing hormone neurones in nonhuman primates. J Neuroendocrinol 2010;22:630-638.

14 McCartney CR: Maturation of sleep-wake gonadotrophin-releasing hormone secretion across puberty in girls: potential mechanisms and relevance to the pathogenesis of polycystic ovary syndrome. J Neuroendocrinol 2010;22:701-709.
15 Eagleson CA, Gingrich MB, Pastor CL, Arora TK, Burt CM, Evans WS, Marshall JC: Polycystic ovarian syndrome: evidence that flutamide restores sensitivity of the gonadotropin-releasing hormone pulse generator to inhibition by estradiol and progesterone. J Clin Endocrinol Metab 2000;85:4047-4052.

16 Gross KM, Matsumoto AM, Bremner WJ: Differential control of luteinizing hormone and follicle-stimulating hormone secretion by luteinizing hormone-releasing hormone pulse frequency in man. J Clin Endocrinol Metab 1987;64:675-680.

17 Spratt DI, Finkelstein JS, Butler JP, Badger TM, Crowley WF Jr: Effects of increasing the frequency of low doses of gonadotropin-releasing hormone $(\mathrm{GnRH})$ on gonadotropin secretion in GnRH-deficient men. J Clin Endocrinol Metab 1987;64:1179-1186.

18 Franks S: Adult polycystic ovary syndrome begins in childhood. Best Pract Res Clin Endocrinol Metab 2002;16:263-272.

19 Witchel SF: Puberty and polycystic ovary syndrome. Mol Cell Endocrinol 2006;254255:146-153.

20 Apter D, Butzow T, Laughlin GA, Yen SS: Accelerated 24-hour luteinizing hormone pulsatile activity in adolescent girls with ovarian hyperandrogenism: relevance to the developmental phase of polycystic ovarian syndrome. J Clin Endocrinol Metab 1994;79: 119-125.

21 Blank SK, McCartney CR, Chhabra S, Helm KD, Eagleson CA, Chang RJ, Marshall JC: Modulation of $\mathrm{GnRH}$ pulse generator sensitivity to progesterone inhibition in hyperandrogenic adolescent girls - implications for regulation of pubertal maturation. J Clin Endocrinol Metab 2009;94:2360-2366. 